\section{Commentary: Double your fun? Management of persistent left superior vena cava during transplantation}

\author{
Stephanie Fuller, MD, MS
}

Surgeons should maintain a repository of techniques for reconstruction of persistent left superior vena cava (PLSVC) during transplantation. Although rare, reimplantation can be complex depending on recipient anatomy. A variety of techniques have been previously described, and the authors herein add to the ingenuous and creative methods devised to preserve systemic venous return from PLSVC either in isolation or in the presence of a diminutive right superior vena cava (RSVC) or in the cases of bilateral superior vena cavae with absent innominate vein.

In the cases in which the PLSVC returns to the coronary sinus, preservation of this continuity is perhaps the most elegant of these methods. As the recipient heart is excised, careful and meticulous dissection is performed of the coronary sinus, preserving its continuity to the PLSVC such that it may either rest in situ or serve as a conduit for reconstruction to the donor RSVC. Previously described by Tanaka and colleagues ${ }^{1}$ with anastomosis of this conduit to the donor right atrial appendage freed of pectinate muscle attachments, this technique allows for autologous tissue reconstruction, which can be particularly helpful in young children still undergoing somatic growth. Tanaka and colleagues $^{1}$ specifically detail use of a suction drainage

From the Perelman School of Medicine at the University of Pennsylvania and Division of Cardiothoracic Surgery, The Children's Hospital of Philadelphia, Philadelphia, Pa.

Disclosures: The author reported no conflicts of interest.

The Journal policy requires editors and reviewers to disclose conflicts of interest and to decline handling or reviewing manuscripts for which they may have a conflict of interest. The editors and reviewers of this article have no conflicts of interest.

Received for publication July 3, 2020; revisions received July 3, 2020; accepted for publication July 7, 2020; available ahead of print July 11, 2020.

Address for reprints: Stephanie Fuller, MD, MS, Division of Cardiothoracic Surgery, The Children's Hospital of Philadelphia, 3401 Civic Center Blvd, Philadelphia, PA 19104 (E-mail: fullers@email.chop.edu).

JTCVS Techniques 2020;3:232-3

2666-2507

Copyright (c) 2020 The Authors. Published by Elsevier Inc. on behalf of The American Association for Thoracic Surgery. This is an open access article under the CC BY-NCND license (http://creativecommons.org/licenses/by-nc-nd/4.0/).

https://doi.org/10.1016/j.xjtc.2020.07.008

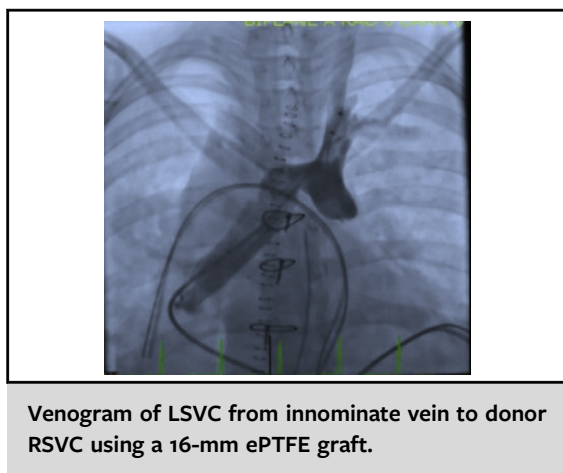

CENTRAL MESSAGE

Preservation of left superior vena cava is technically challenging. Several techniques exist to optimize outcomes while minimizing obstruction to drainage, neurologic sequelae and thrombosis.

tube in the coronary sinus as a reference stent as well as meticulous detail to coronary sinus bleeding from coronary vein branches upon completion of transplantation. Herein, the authors describe anastomosis to the donor RSVC. Maintenance of the coronary sinus connection is also performed while leaving the coronary sinus in situ as a biatrial transplant or an extended inferior vena cava (IVC) anastomosis incorporating both recipient IVC as well recipient coronary sinus en-bloc into the donor IVC. ${ }^{1-4}$ This technique minimizes manipulation of the coronary sinus, which can mitigate bleeding or torsion. A unique situation is one in which the coronary sinus is unroofed or fenestrated to the left atrium and hence complex intracardiac baffle is required to redirect coronary sinus blood to the right atrium. ${ }^{5,6}$

In rare cases, the LSVC is of adequate length to sew anterior to the aorta and pulmonary artery directly to the right atrial appendage after ligation at its insertion to the heart. More commonly, reconstruction may be accomplished by anastomosis prosthetic graft from the donor superior vena cava, innominate vein, or right atrial appendage directly to the PLSVC. ${ }^{5,6}$ This graft may be either biologic or synthetic and may pass either over the great vessels or underneath them. ${ }^{3}$ Caution must be used to assure there is no kinking or stenosis of the LSVC. At the Children's Hospital of Philadelphia, expanded polytetrafluoroethylene interposition grafts are used with 
increasing frequency. We have not experienced conduit obstruction nor thrombosis and grafts have been used as a conduit for endomyocardial biopsy. In the cases in which donor or prosthetic implantation is unavailable, a left bidirectional cavopulmonary anastomosis or Glenn is most often times feasible.

\section{References}

1. Ferraz DLM, Walter FR, Carneiro da Cunha CB. Bicaval orthotopic heart transplantation in a patient with persistent left superior vena cava. J Thorac Cardiovasc Surg Tech. 2020;3:227-9.
2. Tanaka A, Lonchyna VA, Ota T. Persistent left superior vena cava and cardiac transplantation: anterior rerouting with anastomosis to the right atrium. J Heart Lung Transplant. 2015;34:1215-6.

3. Neragi-Miandoab S, Baran D, Godelman A, Goldstein DJ. Orthotopic heart transplantation in patients with persistent left superior vena cava: bicaval and biatrial techniques. Ann Thorac Surg. 2014;97:1085-7.

4. Rabago G, Martin-Trenor A, Lopez-Coronado JL, Macias A, Cosin-Sales J, Herreros JM. Bicaval anastomosis in a heart transplant recipient with left superior vena cava. Ann Thorac Surg. 2002;74:1242-4.

5. Chen J. Heart transplant: transplantation for congenital heart disease. Op Tech Thorac Cardiovasc Surg. 2014;19:P30-46.

6. Vargas FJ. Recosntructive methods for anomalous systemic venous return: surgical management of persistent left superior vena cava. Pediatr Card Surg Ann. 2008;11:31-8. 